\title{
MODIFIKASI DISTRIBUSI MUATAN BERDASARKAN DISTRIBUSI FERMI-DIRAC DAN APLIKASINYA PADA HUKUM GAUSS
}

\author{
Yuant Tiandho ${ }^{1,2^{*}}$, Okky Fajar Tri Maryana ${ }^{3}$, Fitri Afriani ${ }^{1}$, Asep Saefullah ${ }^{4}$, \\ Indra Pardede 3,5 \\ ${ }^{1} J u r u s a n$ Fisika, Universitas Bangka Belitung Bangka, Indonesia \\ ${ }^{2}$ Pusat Kajian Energi dan Teknologi Informasi, Universitas Bangka Belitung, Indonesia \\ ${ }^{3}$ Jurusan Fisika, Institut Teknologi Sumatera Lampung Selatan, Indonesia \\ 4Jurusan Pendidikan Fisika, Universitas Sultan Ageng Tirtayasa Serang, Indonesia \\ ${ }^{5}$ Graduate School of Natural Science and Techonology, Kanazawa University Jepang \\ e-mail: yuant@ubb.ac.id
}

\begin{abstract}
Abstrak
Hukum Gauss merupakan salah satu hukum fundamental fisika, khususnya dalam kajian listrik. Salah satu variabel penting untuk dapat menggunakan hukum Gauss adalah kemampuan menentukan muatan yang terlingkupi permukaan Gauss. Umumnya, definisi distribusi muatan suatu objek didefinisikan oleh fungsi sepenggal (piecewise continuous function). Pada makalah ini diajukan suatu model distribusi muatan yang berlaku untuk di seluruh lokasi. Model tersebut disusun berdasarkan analogi dengan fungsi distribusi Fermi-Dirac. Model yang diajukan mengandung fungsi eksponensial yang terkait dengan radius benda dan dilengkapi dengan suatu parameter untuk menghindari munculnya lekukan kurva yang bersifat tidak fisis. Distribusi muatan tersebut dapat digunakan untuk simulasi menghitung muatan yang terlingkupi oleh permukaan Gauss dan menentukan medan listriknya. Beberapa kasus yang ditinjau adalah objek bola padat serta bola konsentris. Jika dibandingkan dengan distribusi muatan konvensional, distribusi muatan termodifikasi lebih sederhana dan dapat mereduksi algoritma proses komputasi. Oleh karena itu hal ini dapat dimanfaatkan dalam pembuatan media pembelajaran berbasis komputer yang ringkas dan sederhana.
\end{abstract}

Kata kunci: Elektromagnetisme, hukum Gauss, pembelajaran interaktif

\begin{abstract}
Gauss's law is one of the fundamental laws of physics, especially in the study of electricity. One of the important variable to use Gauss's law is the ability to determine the enclosed charge by the Gaussian surface. Commonly, the definition of the charge distribution of an object is defined by piecewise continuous function. In this paper, a charge distribution model that can accommodate all regions is proposed. The model is constructed based on analogies with the Fermi-Dirac's distribution function. The proposed model contains an exponential function that is related to the radius of an object and is equipped with a parameter to avoid the appearance of a not physical curve. The charge distribution can be used to calculate the enclosed charge by the Gaussian surface and to determine its electrical field. Some of the cases reviewed were spherical solid objects and spherical concentric objects. When compared to the conventional charge distribution, the modified distribution is more straightforward, and it can reduce the computational process algorithm. Therefore this can be used to construct concise and simple computer-based learning media..
\end{abstract}

Keywords : Electromagnetism, Gauss's law, interactive education

\footnotetext{
${ }^{*}$ Corresponding author.
} 


\section{PENDAHULUAN}

Gaya elektromagnetik merupakan salah satu gaya fundamental penyusun alam semesta dan telah sangat lama dipelajari (Cajori, 1962; Ciufolini et al., 2013). Berdasarkan catatan sejarah, gejala listrik dan magnet pertama kali dikenal oleh Thales pada 600 SM ketika mengamati amber dan potongan lodestone yang tarik-menarik (Seroglou et al., 1998). Selanjutnya gejala elektromagnetisme terus dipelajari dan terus berkembang berdasarkan pandangan fisika klasik, relativitas Einstein, hingga mekanika kuantum atau teori medan kuantum (Fodor et al., 2016; Hatfield, 2018; Sarabi et al., 2016).

Seringkali pada berbagai buku fisika dasar atau elektrodinamika pembahasan tentang gejala listrik dimulai dari materi Hukum Gauss dan hukum Coulomb (Young \& Freedman, 2012; Griffith, 1999; Halliday et al., 2011). Selain itu, hukum Gauss merupakah salah satu persamaan fundamental yang ikut terangkum dalam persamaan Maxwell (Selvan, 2007) dan hukum Coulomb dapat diturunkan dari persamaan ini (Gupta, 2002). Secara umum teorema yang ditemukan pada tahun 1812 ini (Sarkar et al., 2006) menyatakan hubungan antara distribusi muatan listrik dengan medan listriknya sebagai,

$$
\int_{\text {closed }} \vec{E} \cdot d \vec{A}=\frac{Q_{e n c}}{\varepsilon_{0}}
$$

Pada praktiknya

untuk menggunakan hukum Gauss harus diketahui distribusi muatan yang terlingkupi oleh permukaan Gauss. Dalam pembahasan konvensional, untuk mendefinisikan bentuk distribusi muatan dibutuhkan kata kunci: apakah titik tinjau berada di dalam objek atau di luar objek? Karena pada kenyataannya memang bentuk distribusi muatan di kedua daerah tersebut berbeda. Misalkan untuk suatu bola isolator (diasumsikan muatan pada isolator tersebar secara merata) adalah (Tiandho, 2016),

$$
Q(r)_{\text {isolator }}= \begin{cases}\frac{4}{3} \pi \rho r^{3}, & \text { untuk } r<R \\ Q, & \text { untuk } r \geq R\end{cases}
$$

Sedangkan pada konduktor karena muatan hanya terdapat pada permukaan saja maka distribusi muatan untuk suatu bola yang memiliki radius $R$ didefinisikan sebagai,

$$
Q(r)_{\text {konduktor }}= \begin{cases}0, & \text { untuk } r<R \\ Q & \text { untuk } r \geq R\end{cases}
$$

Tampak bahwa selalu dibutuhkan dua kondisi untuk dapat mendefinisikan nilai muatan pada suatu titik, yaitu pada $r<R$ atau $r \geq R$.

Ketika fungsi distribusi yang terpisah tersebut diterapkan pada suatu simulasi beberapa permasalahan mungkin saja muncul. Seringkali karena harus dilakukan pembatasan maka ketika dibuat suatu bahasa pemrograman membutuhkan logika-logika panjang yang cukup rumit. Kesalahan dalam bahasa pemrograman akan menghasilkan kesalahan yang fatal misal simulasi tidak berjalan atau bahkan berjalan dengan konsep yang tidak tepat sehingga menghasilkan pemahaman yang salah pula. Oleh karena itu, untuk mengatasi kerumitan ungkapan fungsi distribusi muatan konvensional maka penelitian ini bertujuan untuk menghasilkan suatu distribusi muatan baru yang berlaku di seluruh daerah sehingga dapat dilakukan simulasi perhitungan medan listrik menggunakan hukum Gauss. Karena hanya menggunakan satu buah persamaan distribusi muatan maka diperoleh ungkapan tunggal medan listrik yang berlaku pada seluruh kondisi: di dalam dan di luar objek. Sehingga dengan memanfaatkan hasil tersebut maka algoritma simulasi lebih sederhana dibanding apabila menggunakan definisi medan listrik secara konvensional. Validasi fungsi distribusi muatan dilakukan dengan cara menerapkan model tersebut pada beberapa objek simetri bola seperti bola solid konduktor, bola solid isolator, bola konsentris konduktor dan bola konsentris isolator.

Hasil simulasi yang diperoleh diharapkan dapat dimanfaatkan untuk proses pembelajaran fisika berbasis komputer. Pembelajaran dengan menggunakan komputer adalah salah satu inovasi pembelajaran yang saat ini berkembang dengan pesat dan efektif 
dalam membantu peningkatan pemahaman peserta didik (Taufik, 2008; Wahyudin et al., 2010). Untuk melakukan simulasi digunakan software Wolfram Mathematica. Kelebihan software ini adalah relatif mudah karena bahasa pemrogramannya mendekati bahasa sehari-hari dan tersedianya fitur informasi penulisan koding otomatis, mendukung pembuatan dokumen untuk bahan ajar dan presentasi, serta dapat diunggah pada laman Wolfram sehingga hasil simulasi dapat digunakan untuk kalangan yang lebih luas secara gratis (Naa \& Suroso, 2013; Tiandho, 2017).

\section{METODE}

Metode penelitian dibagi menjadi dua yaitu: (1) menentukan model distribusi muatan yang Gauss serta medan listriknya dan (2) menggunakannya dalam simulasi. Untuk menentukan model distribusi muatan digunakan fungsi distribusi Fermi-Dirac (Troy, 2012),

$$
f(E)=\frac{1}{\exp \left[\frac{E-\mu}{k T}\right]+1}
$$

dengan faktor $k T$ menuju nilai yang sangat kecil. Pada praktiknya digunakan sebuah parameter yang analogi dengan faktor $k T$ tetapi bukan dalam bentuk pembagi melainkan pengali. Sehingga apabila $k T$ bernilai sangat kecil maka parameter yang tersebut bernilai sangat besar. Pemilihan tersebut dilakukan agar diperoleh kurva distribusi yang dapat berubah secara signifikan pada suatu titik tinjau, dalam kasus ini, pada radius objek. Setelah distribusi muatan yang terlingkupi oleh permukaan Gauss diperoleh maka dilakukan perhitungan medan listrik di seluruh daerah objek menggunakan hukum Gauss. Secara umum, hasil medan listrik yang dikaji secara analitik berupa suatu persamaan distribusi medan listrik yang berlaku untuk daerah di dalam objek maupun di luar objek. Agar kajian memiliki manfaat langsung maka distribusi tersebut diuji pada simulasi bola isolator dan konduktor serta bola konsentris isolator dan konduktor.

Proses simulasi dilakukan secara sederhana dengan memasukkan hasilhasil tersebut dalam bentuk plot muatan terlingkupi dan plot medan listrik tetapi dengan variasi ukuran objek dan muatan total atau rapat muatannya. Penambahan pilihan manipulasi variabel dilakukan agar simulasi dapat lebih mudah untuk dijalankan. Simulasi dilakukan dengan perangkat lunak Wolfram Mathematica pada komputer Intel Core i7 $8750 \mathrm{H}$ dengan RAM 16 GB. Secara terperinci algoritma dari proses simulasi menggunakan Wolfram Mathematica seperti pada Gambar 1.

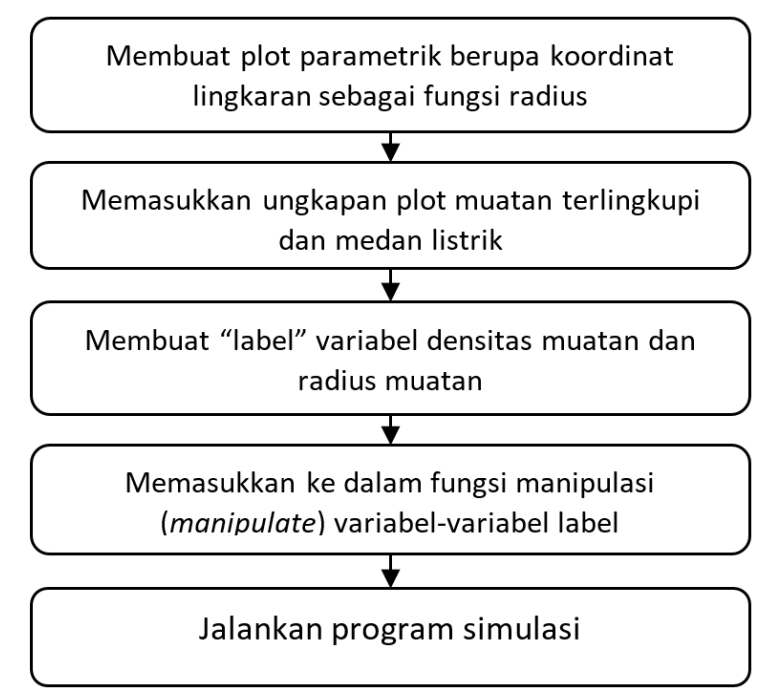

Gambar 1. Algoritma simulasi dengan Wolfram Mathematica 


\section{HASIL DAN PEMBAHASAN}

Sebelum dipilih ungkapan distribusi muatan yang akan digunakan dalam penelitian ini diuji karakteristik fungsi distribusi muatan yang analogi dengan pers. (4). Untuk bola padat isolator homogen dengan bentuk distribusi muatan seperti pada pers. (2) maka ungkapan dari muatan bola isolator dapat dinyatakan sebagai (Tiandho, 2016),

$$
Q_{\text {enc }}=\frac{4}{3}\left(\frac{\pi \rho r^{3}}{1+\exp [\alpha(r-R)]}+\frac{\pi \rho R^{3}}{1+\exp [\alpha(R-r)]}\right)
$$

dengan $r$ adalah titik tinjau, $R$ adalah jarijari bola isolator, $\rho$ adalah rapat muatan, dan $\alpha$ merupakan parameter fungsi yang menentukan bentuk dari suatu distribusi. Pada dasarnya parameter fungsi $\alpha$ berkaitan dengan variabel $k T$ pada persamaan Fermi-Dirac. Pada distribusi Fermi-Dirac semakin kecil suku $k T$ maka kurva distribusi yang dihasilkan akan berubah secara tajam pada suatu titik. Sebagai perbandingan, pada Gambar 2 disajikan bentuk distribusi muatan pada berbagai nilai parameter $\alpha$. Semakin besar nilai $\alpha$ maka bentuk kurva distribusi yang diperoleh semakin tegas membedakan bentuk distribusi muatan untuk $r<R$ serta $r>R$. Untuk nilai $\alpha=10$ kurva tampak masih memiliki lekukan seperti punuk yang begitu besar sehingga kurang sesuai untuk menggambarkan pola distribusi muatan. Karena dengan adanya lekukan pada kurva tersebut akan memunculkan suatu nilai maksimum muatan di sekitar $r$

Enclosed charge (nC)

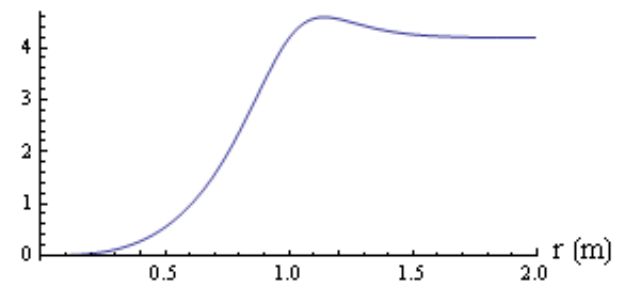

(a)

Enclosed charge (nC)

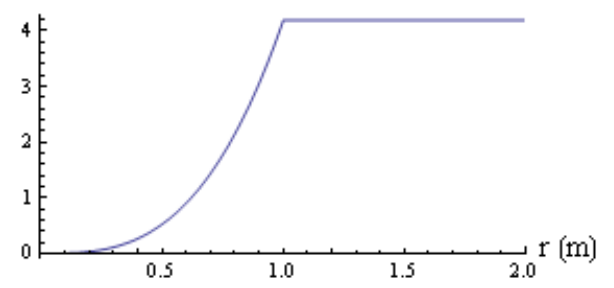

(c)
$=R$ dan kemudian nilainya kembali menurun ketika kondisi $r>R$. Padahal seharusnya, pada kasus $r<R$ maka distribusi muatan bersifat kontinu dan untuk kasus $r>R$ maka nilai muatan konstan. Dengan memperbesar nilai $\alpha$ seperti pada Gambar 2(b) sampai 2(d) tampak lekukan punuk (hump-shaped curve) semakin mengecil bahkan hilang ketika nilai a menuju tak hinggga. Sehingga dapat dinyatakan bahwa untuk dapat memperoleh kurva distribusi muatan tunggal yang sesuai dengan bentuk pers. (2) maka dapat digunakan nilai $\alpha \rightarrow \infty$. Hasil ini dapat diperoleh karena ketika digunakan nilai konstanta $\alpha \rightarrow \infty$ untuk kasus $r<R$ maka hanya suku pertama saja yang tersisa sedangkan suku kedua lenyap. Lenyapnya suku kedua ini dapat terjadi dengan mengingat pada kasus $r<$ $R$ maka nilai $r-R$ selalu bernilai negatif sedangkan untuk nilai $R-r$ selalu bernilai positif. Sehingga dengan memanfaatkan sifat dari limit eksponensial,

$$
\lim _{\alpha \rightarrow \infty} \exp [a x]=\infty
$$

dan

$$
\lim _{\alpha \rightarrow \infty} \exp [-\alpha x]=0
$$

dengan $x$ merupakan variabel yang bernilai positif. Berdasarkan hasil tersebut maka bentuk dari distribusi muatan yang awalnya terdiri dari dua kondisi (Young \& Freedman, 2012) seperti pada pers. (2) dapat dinyatakan menjadi hanya sebuah persamaan saja.

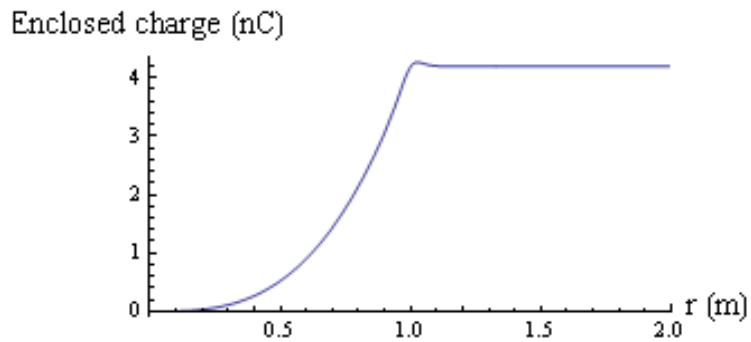

(b)

Enclosed charge (nC)

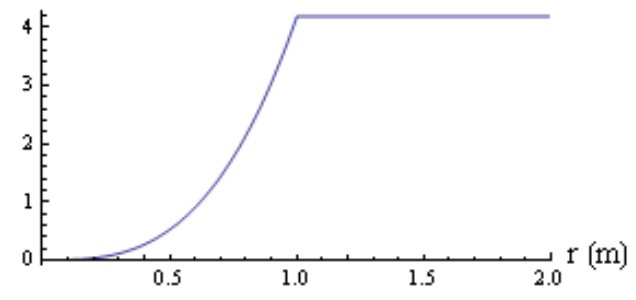

(d) 
Gambar 2. Bentuk muatan yang dilingkupi oleh permukaan Gauss untuk bola isolator dengan $R=1 \mathrm{~m}$ serta $\rho=1 \mathrm{nC} / \mathrm{m}^{3}$ : (a) $\alpha=$ Hukum Gauss pada bola padat

Untuk menunjukkan keumuman fungsi distribusi muatan dibahas bola padat yang berupa isolator dan konduktor secara eksplisit. Untuk bola padat isolator

$$
\text { 10, (b) } \alpha=100,(\mathrm{c}) \alpha=1000, \text { dan (d) limit }
$$

diasumsikan muatan tersebar secara merata sehingga muatan yang dilingkupi oleh suatu permukaan Gauss pada jarak $r$ dapat didefinisikan sebagai,

$$
Q_{\text {enc }}(r)=\lim _{\alpha \rightarrow \infty}\left(\frac{4 \pi \rho r^{3}}{3(1+\exp [\alpha(r-R)])}+\frac{4 \pi \rho R^{3}}{3(1+\exp [\alpha(R-r)])}\right)
$$

dengan $\rho$ adalah rapat muatan objek sedangkan $R$ adalah jari-jari objek padat tersebut. Pada persamaan di atas muncul suku $\alpha$ yang nilainya menuju limit tak hingga karena hal ini bersesuaian dengan bentuk kurva seperti pada Gambar 2.
Apabila muatan yang dilingkupi oleh permukaan Gauss dinyatakan oleh pers. (8) maka dengan mudah dapat ditentukan sebaran medan listrik akibat objek tersebut menggunakan hukum Gauss pada pers. (1) sehingga diperoleh

$$
E(r)=\lim _{\alpha \rightarrow \infty} \frac{1}{4 \pi \varepsilon_{0} r^{2}}\left(\frac{4 \pi \rho r^{3}}{3(1+\exp [\alpha(r-R)])}+\frac{4 \pi \rho R^{3}}{3(1+\exp [\alpha(R-r)])}\right)
$$

Seperti pada fungsi distribusi muatan, suku pertama pada pers. (9) menunjukkan nilai medan listrik untuk daerah di dalam objek sedangkan suku kedua menunjukkan nilai medan listrik di luar objek. Kedua suku tersebut memberikan kontribusi secara bergantian sesuai dengan titik tinjau $r$.

Pemanfaatan dari kedua persamaan yang telah diperoleh dalam makalah ini adalah dilakukan simulasi hukum Gauss dengan menggunakan Wolfram Mathematica dan hasilnya ditunjukkan oleh Gambar 3. Di dalam simulasi yang dibuat tersedia menu untuk mengubahubah nilai densitas muatan dari bola isolator serta radiusnya. Sehingga dengan adanya menu ini akan memudahkan peserta didik untuk memahami pengaruh perubahan densitas muatan dan radius bola terhadap medan listriknya.

Pada hasil simulasi tampak di dalam objek bola padat isolator, muatan yang dilingkupi oleh permukaan Gauss semakin meningkat seiring $r^{3}$ hingga pada radius objek $R$. Setelah melewati $R$ maka tampak jelas bahwa muatan yang dilingkupinya bernilai konstan. Hal ini menunjukkan bahwa di luar objek tidak terdapat muatan lagi atau dengan kata lain untuk kajian di luar objek dapat digunakan muatan total dari bola isolator. Sedangkan untuk medan listriknya, di dalam objek nilainya akan meningkat secara linier sedangkan untuk daerah di luar objek akan menurun secara kuadratik. Kesesuaian hasil ini disebabkan oleh penggunaan limit $\alpha \rightarrow \infty$ yang membuat pers. (9) mereduksi menjadi $E_{i n}=\rho r / 3 \varepsilon_{0}$ untuk kasus $r<R$ dan akan mereduksi menjadi $E_{\text {out }}=Q / 4 \pi \varepsilon_{0} r^{2}$ untuk kasus $r>R$, dengan $Q$ adalah muatan total isolator. Hasil ini sesuai dengan hasil tinjauan medan listrik konvensional yang menggunakan fungsi distribusi muatan secara terpisah (Young \& Freedman, 2012). Dengan menggunakan fungsi distribusi muatan yang diajukan maka untuk melakukan simulasi dapat digunakan algoritma yang sangat sederhana karena hanya dibutuhkan sebuah fungsi untuk menggambarkan distribusi muatan yang dilingkupi oleh permukaan Gauss dan medan listriknya di seluruh area titik tinjau. 


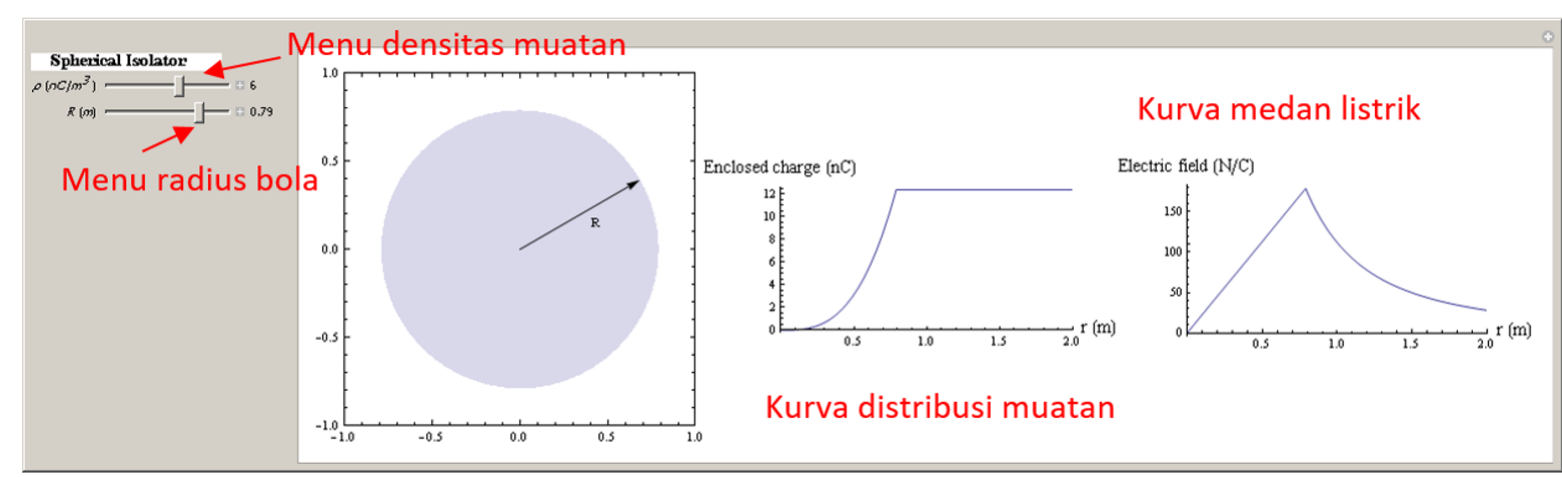

Gambar 3. Simulasi hukum Gauss pada bola padat isolator

Sebagai perbandingan, juga dilakukan simulasi untuk bola konduktor. Pada konduktor muatan hanya terdapat di permukaan saja (Halliday et al., 2011). Sehingga secara otomatis suku pertama pada pers. (9) tidak memberikan kontribusi dan hanya menyisakan suku kedua saja,

$$
Q_{\text {enc }}(r)=\lim _{\alpha \rightarrow \infty} \frac{Q}{(1+\exp [\alpha(R-r)])}
$$

dengan $Q$ adalah muatan total bola konduktor. Dengan menggunakan metode yang sama medan listrik pada bola konduktor dapat dituliskan sebagai,

$$
E(r)=\lim _{\alpha \rightarrow \infty} \frac{1}{4 \pi \varepsilon_{0} r^{2}} \frac{Q}{(1+\exp [\alpha(R-r)])}
$$

Hasil simulasi dari pers. (10) dan (11) menggunakan dapat dilihat pada Gambar 4. Tampak bahwa apabila permukaan Gauss berada di dalam bola konduktor maka muatan yang terlingkupi adalah nol. Kemudian tepat di permukaan bola maka muatannya meningkat secara tajam dan diikuti nilai yang konstan untuk daerah di luar bola konduktor. Medan listrik pada bola konduktor baru muncul di permukaan bola dan nilainya terus menurun secara kuadratik untuk daerah di luar bola konduktor.

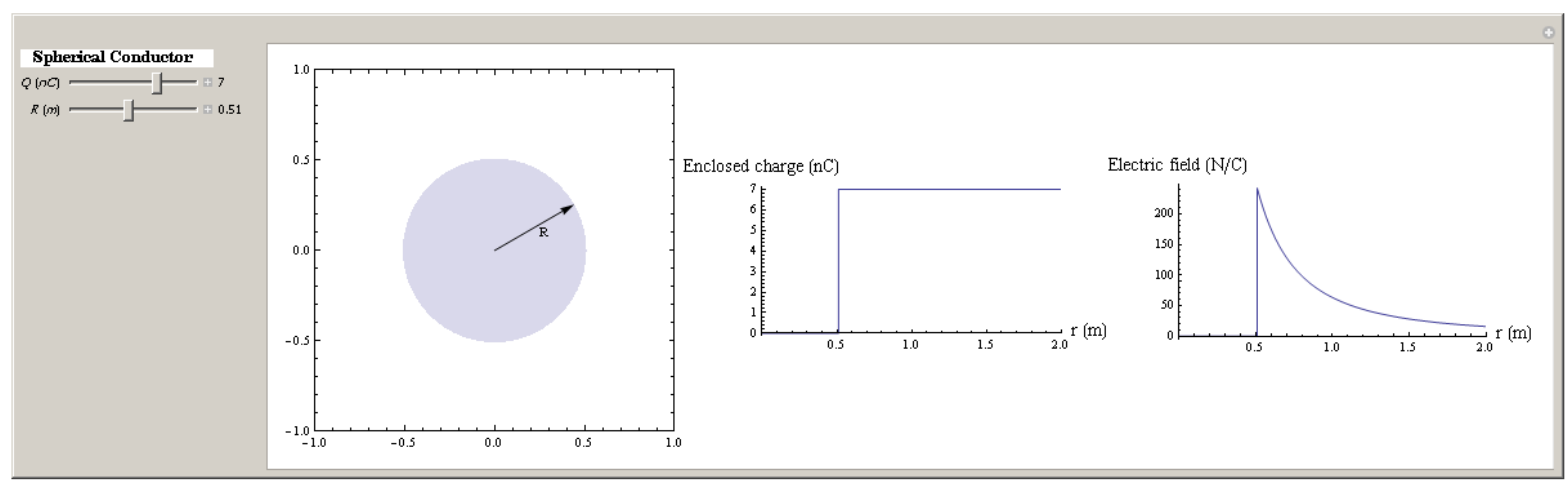

Gambar 4. Simulasi hukum Gauss pada bola konduktor

\section{Hukum Gauss pada Bola Konsentris}

Bola konsentris yang disimulasikan di sini terdiri dari dua bola sepusat dimana bola pertama yang lebih kecil adalah bola padat sedangkan lainnya adalah bola berongga. Bola pertama memiliki radius $c$ sedangkan bola kedua memiliki radius dalam $b$ dan radius luar $a$ atau $c<b<a$.
Seperti pada bola padat, pada bola konsentris dilakukan analisis untuk isolator dan konduktor. Dengan asumsi bola isolator memiliki rapat massa homogen maka sistem bola konsentris seperti didefinisikan di atas akan memiliki fungsi muatan yang terlingkupi oleh permukaan Gauss sebagai, 


$$
Q_{\text {enc }}(r)=\lim _{\alpha \rightarrow \infty}\left(\begin{array}{l}
\frac{4 \pi \rho_{1} r^{3}}{3(1+\exp [\alpha(r-c)])}+\frac{4 \pi \rho_{1} c^{3}}{3(1+\exp [\alpha(c-r)])}+\frac{4 \pi \rho_{2}\left(r^{3}-b^{3}\right)}{3(1+\exp [\alpha(b-r)])} \\
+\frac{4 \pi \rho_{2}\left(a^{3}-r^{3}\right)}{3(1+\exp [\alpha(a-r)])}
\end{array}\right)
$$

Suku pertama pada persamaan di atas menunjukkan muatan yang terlingkupi untuk daerah di dalam bola padat kecil. Apabila suku tersebut memberi kontribusi maka ketiga suku lainnya akan bernilai nol karena $a>c$ begitu pula $b$. Suku kedua menunjukkan muatan yang terlingkupi untuk daerah di luar bola kecil secara umum. Ketika suku kedua memberikan kontribusi maka suku pertama akan menuju nol karena nilai eksponensial dari suku pertama akan menuju tak hingga (selisih $r$ dan $c$ bernilai positif). Adapun suku ketiga dan keempat masing-masing mendeskripsikan distribusi muatan yang diberikan oleh bola berongga besar. Sehingga melalui pers. (12) maka medan listrik di seluruh daerah bola konsentris dapat ditentukan dengan menggunakan hukum Gauss sebagai,

$$
E(r)=\lim _{\alpha \rightarrow \infty} \frac{1}{4 \pi \varepsilon_{0} r^{2}}\left(\begin{array}{l}
\frac{4 \pi \rho_{1} r^{3}}{3(1+\exp [\alpha(r-c)])}+\frac{4 \pi \rho_{1} c^{3}}{3(1+\exp [\alpha(c-r)])}+\frac{4 \pi \rho_{2}\left(r^{3}-b^{3}\right)}{3(1+\exp [\alpha(b-r)])} \\
+\frac{4 \pi \rho_{2}\left(a^{3}-r^{3}\right)}{3(1+\exp [\alpha(a-r)])}
\end{array}\right)
$$

Apabila fungsi muatan yang terlingkupi oleh permukaan Gauss dan medan listrik pada bola konsentris isolator diaplikasikan untuk proses simulasi maka hasilnya ditunjukkan oleh Gambar 5. Pada simulasi ini tampak bahwa variabel yang dapat diubah adalah rapat muatan bola konsentris (besar dan kecil), radius $c$ bola kecil, dan radius $b$ bola besar. Adapun untuk radius a ditetapkan bernilai 1 untuk menyederhanakan permasalahan tanpa mengurangi esensi proses simulasi. Untuk muatan yang terlingkupi oleh permukaan Gauss pada bola konsentris isolator tampak bahwa nilainya akan meningkat ketika titik tinjaunya berada di dalam bola kecil, kemudian bernilai konstan ketika titik tinjau berada di antara bola kecil dan bola besar dan kembali meningkat ketika titik tinjau berada di dalam bola besar lalu akan bernilai konstan lagi ketika titik tinjau berada di luar bola konsentris. Hal ini sesuai dengan aspek fisis yang diharapkan

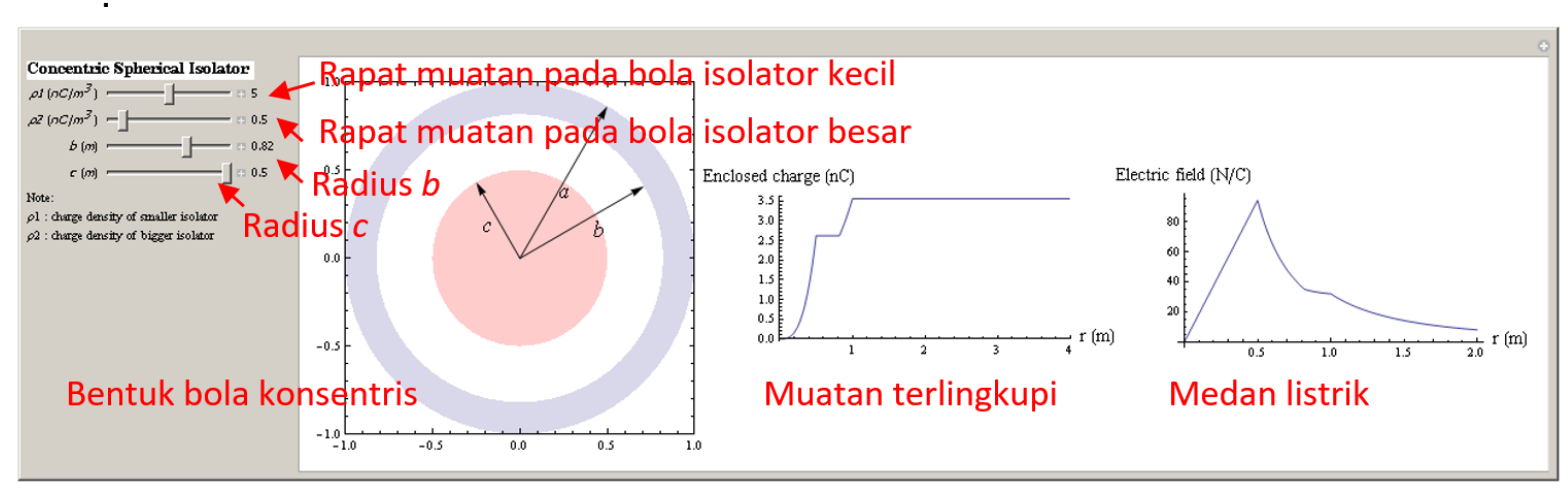

Gambar 5. Simulasi hukum Gauss pada bola konsentris isolator

Pada Gambar 5 tampak bahwa medan listrik sebagai fungsi titik tinjau $r$ ketika di dalam bola isolator kecil nilainya akan terus meningkat. Ketika diluar bola kecil medan listriknya akan semakin menurun. Tetapi dapat dilihat bahwa untuk titik tinjau dimana bola besar berongga memberikan kontribusi muatan penurunan 
medan listriknya lebih landai dibanding medan listrik pada $r$ yang terletak di antara bola kecil dan bola besar. Hal ini dapat terjadi karena pada titik tinjau tersebut muatan yang dilingkupi oleh permukaan Gauss bernilai lebih besar. Namun demikian, kesimpulan ini tidak dapat digeneralisir karena tinjauan kasus ini juga bergantung pada jenis muatan yang terdapat pada masing-masing bola serta nilai rapat muatannya.

Pada bola konsentris konduktor karena muatannya hanya terdapat di permukaan-permukaan bola saja maka fungsi distribusi muatan yang terlingkupi oleh permukaan Gauss-nya dapat dinyatakan secara lebih sederhana sebagai,

$$
Q_{\text {enc }}(r)=\lim _{\alpha \rightarrow \infty}\left(\frac{q}{1+\exp [\alpha(c-r)]}-\frac{q}{1+\exp [\alpha(b-r)]}+\frac{q+Q}{1+\exp [\alpha(a-r)]}\right)
$$

Sehingga dengan menggunakan

hukum Gauss medan listrik yang

ditimbulkan oleh bola konsentris konduktor sebagai fungsi titik tinjau $r$ dapat diturunkan sebagai,

$$
E(r)=\lim _{\alpha \rightarrow \infty} \frac{1}{4 \pi \varepsilon_{0} r^{2}}\left(\frac{q}{1+\exp [\alpha(c-r)]}-\frac{q}{1+\exp [\alpha(b-r)]}+\frac{q+Q}{1+\exp [\alpha(a-r)]}\right)
$$

dengan q adalah muatan total bola kecil (bola padat) dan $Q$ adalah muatan total bola besar (bola berongga). Jika kedua fungsi tersebut digunakan untuk melakukan simulasi hukum Gauss maka hasilnya akan tampak seperti pada Gambar 6. Dapat dilihat dengan jelas bahwa untuk muatan di dalam bola konduktor, baik pada bola kecil maupun bola besar, keduanya selalu bernilai nol. Muatan listrik hanya muncul ketika permukaan Gauss memiliki titik tinjau yang berada di luar bola-bola tersebut. Begitu pula dengan medan listriknya. Medan listrik pada bola konsentris konduktor akan bernilai hanya untuk titik tinjau di luar kedua bola

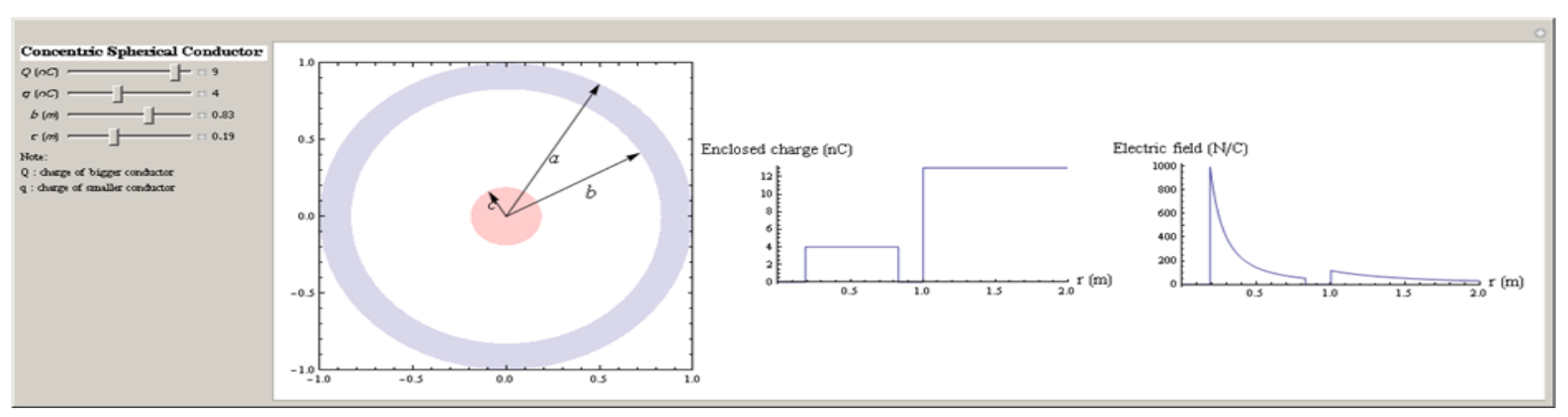

Gambar 6. Simulasi hukum Gauss pada bola konsentris konduktor

\section{SIMPULAN}

Melalui modifikasi fungsi distribusi Fermi-Dirac telah berhasil diperoleh fungsi distribusi muatan yang berlaku di seluruh titik tinjau. Fungsi distribusi muatan yang umumnya harus dipisah untuk kondisi di dalam objek dan di luar objek dapat dirangkum menjadi sebuah fungsi tunggal melalui penggunaan parameter fungsi $\alpha$ dengan nilai menuju tak hingga. Penggunaan limit tak hingga tersebut untuk menghindari munculnya lekukan punuk yang menyebabkan distribusi muatan menjadi tidak sesuai dengan kaidah fisis. Berdasarkan hukum Gauss, fungsi distribusi muatan ini dapat digunakan untuk menentukan medan listrik di seluruh titik tinjau. Karena hanya 
mengandung sebuah fungsi saja maka proses simulasi hanya membutuhkan algoritma yang sangat sederhana. Pengujian pada berbagai kasus seperti pada bola padat serta bola konsentris, baik untuk konduktor maupun isolator, menunjukkan bahwa fungsi distribusi yang diajukan sesuai dengan literatur. Selanjutnya diharapkan para pendidik dapat memanfaatkan bentuk distribusi muatan yang diajukan untuk melakukan simulasi-simulasi materi pembelajaran untuk mendukung proses belajar mengajar menjadi lebih baik

\section{DAFTAR PUSTAKA}

Cajori, F. 1962. A History of Physics. New York: Dover Publication.

Ciufolini, I., Paolozzi, A., Koenig, R., Pavlis, E. C., Ries, J., \& Matzner, R. 2013. Fundamental physics and general relativity with the LARES and LAGEOS satellites. Nuclear Physics B, 243, 180-193.

Fodor, Z., Hoelbing, C., Katz, S. D., Lellouch, L., Portelli, A., Szabo, K.K., \& Toth, B. C. 2016. Quantum electrodynamics in finite volume and nonrelativistic effective field theories. Physics Letters B, 755, 245-248.

Griffith, D. J. 1999. Introduction to Electrodynamics (3rd ed.). New Jersey: Prentice Hall.

Gupta, M. S. 2002. A fable from vector valley. IEEE Microwave Magazine, December, 18-22.

Halliday, D., Resnick, R., \& Walker, J. 2011. Fundamentals of Physics (9 ed.). USA: John Wiley \& Sons, Inc.

Hatfield, B. 2018. Quantum Field Theory of Point Particles and Strings. Boca Raton: CRC Press.

Naa, C. F. \& Suroso, A. 2013. Pembelajaran fisika berbasis

Wolfram Mathematica 8.0. Prosiding Seminar Kontribusi Fisika 2013, 5460.

Sarabi, B., Ramayanaka, A. N., Burin, A. L., Wellstood, F. C., \& Osborn, K. D. 2016. Projected dipole moments of individual two-level defects extracted using circuit quantum electrodynamics. Physical Review Letters, 167002.

Sarkar, T., Mailloux, R., Oliner, A. A., Palma, M. S., \& Sengupta, D. L. 2006. History of Wireless. New York: John Wiley \& Sons.

Selvan, K. T. 2007. Engineering education: presentation of Maxwell's equations in historical prespective and the likely desirable outcomes. IEEE Antennas and Propagation Magazine , 49(5), 155-160.

Seroglou, F., Koumaras, P., \& Tselfes, V. 1998. History of science and instructional design: the case of electromagnetism. Science \& Education, 7, 261-280.

Taufik, M. 2008. Pembuatan media pembelajaran berbasis compact disc untuk menampilkan simulasi dan virtual labs besaran-besaran fisika. Jurnal Pijar MIPA, III(1), 23-29.

Tiandho, Y. 2016. Modifikasi distribusi massa pada objek simetri bola. Jurnal Pendidikan Fisika, 4(2), 7685.

Tiandho, Y. 2018. Analisis kuantitatif pori berdasarkan pengolahan citra menggunakan Wolfram Mathematica. Kumpulan Jurnal IImu Komputer, 4, 15-23.

Troy, W. C. 2012. Low temperature properties of the Fermi-Dirac, Boltzmann and Bose-Einstein equations. Physics Letters $A, 376$, 2887-2893.

Wahyudin, Sutikno, \& Isam, A. 2010. Keefektifan pembelajaran berbantuan multimedia menggunakan metode inkuiri terbimbing untuk meningkatkan minat dan pemahaman siswa. Jurnal Pendidikan Fisika Indonesia, 6, 5862.

Young, H. D. \& Freedman, R. A. 2012. Sears and Zemansky's University Physics: with Modern Physics. San Fransisco: Addison-Wesley. 